\title{
How effective is central bank communication in emerging economies? An empirical analysis of the chinese money markets responses to the people's bank of China's policy communications
}

\author{
Shiwei Su${ }^{1} \cdot$ Ahmad Hassan Ahmad ${ }^{1} \cdot$ Justine Wood ${ }^{1}$
}

Published online: 8 May 2019

(C) The Author(s) 2019

\begin{abstract}
Central banks, in both developed and developing economies, are responding to the increased demand for transparency in monetary policy formulation and implementation. It is argued that central bank communication enhances market efficiency and calms down market volatility. This paper investigates to what extent that the People Bank of China's (PBC) communication influences the Chinese money market. Three communication indexes were constructed and used in the empirical analysis. The findings indicate that the PBC's communication has a significant effect on the country's money market. Secondly, informal communication appears to be more effective than formal communication. Overall, the results suggest that policy makers and market observers could pay much more attention to the informal communications, such as speeches of the bank's officials, than formal ones, such as the bank's report and minutes.
\end{abstract}

Keywords Central bank communication - Credibility · The PBC · Chinese money market . Central bank communication strategies

JEL Classification E52 $\cdot$ E58 $\cdot$ E61

\section{Introduction}

Central banks' transparency was not treated with importance until recently, and monetary policymaking was largely conducted with secrecy. However, since the 1990s, there is a trend that central banks of the developed economies have been trying to promote transparency in the way monetary policy is conducted. Policy formulation and implementation are communicated to the economic agents with the view to enhance the effectiveness of

We are grateful to the editor and the anonymous reviewer for their very useful and constructive comments.

Ahmad Hassan Ahmad

A.H.Ahmad@lboro.ac.uk

1 School of Business \& Economics, Loughborough University, Leicestershire LE11 3TU, UK 
the policy (Geraats 2006). Accordingly, procedural and policy implementation has been handled with greater transparency than in the past. In line with this, central banks disclose information to the public on its activities, such as rationales behind policy decisions, economic outlook, and monetary policy inclination. This is not only in response to demand for more transparency by the markets, but authorities are also realising the usefulness of central bank communication in promoting the effectiveness of monetary policy.

Central bank communication is the provision of information by central banks to the public on policy issues that include objectives of monetary policy, etc. via formal and informal channels, such as written reports, press conferences and speeches (De Haan et al. 2007). ${ }^{1}$ The important role played by the communication is to manage market expectations, which matter for financial markets and the entire economy (Blinder 1998). Therefore, wellcommunicated information makes markets become more efficient as it reduces uncertainty and lowers volatility and, therefore, helps central banks achieve part of its monetary policy objectives (Kahn 2007). This is because provision of accurate and credible information reduces asymmetric information by signalling the banks' policies, economic outlook, etc. These have been considered by researchers (e.g., Andersson et al. 2006; Siklos and Bohl 2007; Lamla and Lein 2011; Neuenkirch 2013) and generally report that communications have effects on financial markets both in the short and long terms.

Therefore, central bank communication has received increasing attention in both theoretical and empirical research. For example, some papers investigate aspects of central bank communication, such as the economic outlook. (e.g., Rosa 2011; Hayo et al. 2012; Campbell et al. 2012; Masawi et al. 2018). Another area of communication is the channels, which investigate the effects of communication strategies (e.g., De Haan 2008; Berger et al. 2011a, b). The issue of "how-to-communicate" is dealt with as either formal or informal communication. ${ }^{2}$ Most of the research, however, focuses on formal communication such as the minutes and inflation reports (Reeves and Swicki 2007), financial stability reports (Born et al. 2012) and press conferences (e.g., Conrad and Lamla 2010; Berger et al. 2011a, b; Hussain 2011). However, there is no consensus from the results, which necessitates further investigation (e.g., Ehrmman and Fratzscher 2007; Hayo and Neuekirch 2011a, b). Furthermore, the existing findings on effective channels of communication reported mixed results. For example, Reeves and Swicki (2007) report that the Bank of England's (BOE) speeches have less effect relative to the bank's minutes and inflation reports on the UK financial markets whereas Hayo et al. (2010) find that speeches of the European Central Bank's (ECB) officials have larger effect than reports and testimonies on the EU and Pacific markets.

Extant literature mainly focuses on developed economies and their central banks, such as the ECB, the BOE and the Federal Reserve (the Fed). As argued by Neuekirch (2011) and Knutter et al. (2011) central bank communication is equally fundamental for emerging economies for the effective implementation of their monetary policy whose impact would be felt beyond their shores. This is particularly important when their output constitutes a significant proportion of the global output. For example, China, the subject of this paper, is the second largest economy in terms of output after the US. Therefore, this paper fills in this gap by investigating effectiveness of the Chinese central bank communication on

\footnotetext{
1 Formal and informal communication has been widely used in empirical and conceptual research where formal refers to regularized and structured modes of communication while informal ones are those perceived as spontaneous and nonregularized.

2 Refer to footnote 1 above.
} 
China's money markets. Existing literature on efficient market hypothesis, such as Zeng and McLaren (2015), suggests that Chinese markets are not only sensitive to information but also react in response, accordingly. This is in similar fashion to established findings in the efficiency market hypothesis. Recent evidence that supports this includes (Steeley 2004; Kadapakkam et al. 2015).

The main findings of the paper are the following. The results suggest that the Peoples Bank of China's (PBC) deeds tally with their words; where words indicating a change to contractionary or otherwise is followed by the respective actions. Secondly, the PBC's communication is found to influence the Chinese interbank money market. Thirdly, informal communication shows a larger effect in general, but more particularly for monetary policy stances. Lastly, communication strategies are significant in influencing the interbank money market, but effect of diverse communication seems to exist.

The remainder of the paper is organized as follows. Section 2 provides a brief background on the evolution and structure of the PBC. Section 3 discusses methodology and empirical strategies adopted in the paper. Section 4 discusses data and explains the construction of the communication indexes. Section 5 investigates whether the PBC's words tally with their deeds, and if the institution is therefore credible. Section 6 presents and discusses the estimated results. Section 7 concludes and confers policy implication.

\section{Evolution of people's bank of China and its structure}

The People's Bank of China (PBC) was established on December 1, 1948 as a product of merging three banks; the Huabei Bank, the Beihai Bank and the Xibei Farmer Bank. In September 1983, the State Council decided to have its function as a central bank. In the 8th National People's Congress, the PBC was legally confirmed the central bank status. There are twenty departments in $\mathrm{PBC}$ including the monetary policy department, the financial stability, and the international department.

One of the departments is the monetary policy department. Its main responsibilities consist of, for example, setting intermediate targets of monetary policy and coordinating efforts to achieve targets, proposing options of monetary policy instruments and organizing implementations, formulating of interest rate policy and administrative rules for RMB and foreign currencies as well as RMB exchange rate policy, etc. PBC's monetary policies objectives and main goals are generally in line with major central banks around the world. Precisely, it aims to achieve a stable price level, full employment, economic growth and sustainable international accounts.

The monetary policy committee (MPC) of the PBC is not only saddled with the responsibility of formulating and implementing the Chinese monetary policy, but also is responsible for the monetary policy communication. The sixteen-member committee holds a quarterly meeting; however, the policy decision is not changed regularly. Formal ${ }^{3}$ communications of the PBC are mainly the quarterly minutes of the committee's meeting, quarterly monetary policy reports, financial stability reports and annual reports. Informal communications of the PBC are testimonies that summarize economic stances of the previous quarter and signals key changes in the next quarter, conferences, interviews and speeches that are mostly given by the governor. An important difference between the formal and

\footnotetext{
3 This is based on the definition in footnote 1.
} 
informal communications is the fact that the former is less frequent but more structured while the latter is more frequent, less or no structure and, therefore, flexible. The different nature of these communication channels and their related effect are of interest to the literature, which is the main object of the 'how-to-communicate' question. Although the definition and grouping of central bank communications into formal and informal is standardised in the literature for comparison purposes, it is worth noting that this can vary across central banks' environment.

In addition to formulating and implementing monetary policy, the PBC also serves other functions of central banking that include issuing of the country's currency, the Renminbi (RMB) and administering its circulation, managing of, preventing and mitigating systemic financial risks.

\section{The empirical methodology}

In line with the relevant papers in central bank communications (e.g., Hayo et al. 2012; Ehrmann and Fratzscher 2013) and given its ability to accommodate volatilities, issues of heteroskedasticity, excess kurtosis and skewness, generalized autoregressive conditional heteroskedasticity (GARCH) type models are adopted for our analysis. This is mainly because, firstly, the GARCH models would capture skewness and kurtosis of series, and secondly, they are easily employed. Specifically, the paper follows Ehrmann and Fratzscher (2007), Hayo et al. (2012) and Buchel (2013) by using exponential generalized autoregressive conditional heteroscedastic (EGARCH) models, which have the advantage of no nonnegativity constraints on the coefficients. The mean equation can be represented as:

$$
r_{t}=a+\eta r_{t-1}+\beta_{i} \operatorname{Com}_{t}^{i}+\gamma Z_{t}+\varepsilon_{t}
$$

where $i=3, r_{t}$ is the Shanghai Interbank Offer Rates (SHIBOR) rate, and $\mathrm{r}_{\mathrm{t}-1}$ is its lagged rates. $\operatorname{Com}_{t}^{i}$ denotes communication indexes and $Z_{t}$ is the vector of control variables. The communication indexes and its construction are explained in Sect. 4. The conditional mean model in (1) links the SHIBOR rate to its past rates, the communication indexes and the control variables, which include the announcement of macroeconomics news (e.g., CPI, GPD). ${ }^{4}$ Incorporating these control variables into the model is not only the practice in the literature, but they have also been found to be significant factors that impact on the financial markets and help in identifying true effects of the communication indexes with the parameters of interest, $\beta_{i}$ (see for example, Ehrmann and Fratzscher 2007; Hayo et al. 2012; Buchel 2013).

The variance of a GARCH model in Eq. (1) can be written as:

$$
\sigma_{t}=a_{2}+a_{3} \varepsilon_{t-1}+a_{4} \sigma_{t-1}+\lambda_{i} \sum_{i} \text { Comdays }_{t}^{i}+\gamma Z D_{t}^{h}
$$

where the variables are as defined above. The variance of an EGARCH model is given as:

$$
\log \left(\sigma_{t}\right)=\omega+a_{5} \log \left(\sigma_{t-1}^{2}\right)+a_{6}\left[\frac{\left|\mu_{t-1}\right|}{\sqrt{\sigma_{t-1}^{2}}}-\sqrt{\frac{2}{\pi}}\right]+a_{7} \frac{\left|\mu_{t-1}\right|}{\sqrt{\sigma_{t-1}^{2}}}+\lambda_{i} \sum_{i} \text { Comdays }_{t}^{i}+\gamma Z D_{t}^{h}
$$

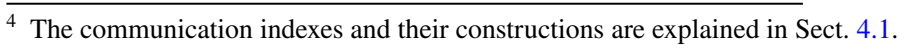


Table 1 SHIBOR from overnight to $1 \mathrm{Y}$

\begin{tabular}{lcclc}
\hline Series & Mean & SD & Maximum & Minimum \\
\hline O/N & 2.77 & 1.09 & 9.58 & 1.03 \\
$1 \mathrm{~W}$ & 3.45 & 1.22 & 9.07 & 1.36 \\
$2 \mathrm{~W}$ & 3.78 & 1.32 & 9.06 & 1.41 \\
$1 \mathrm{M}$ & 4.23 & 1.34 & 9.70 & 1.74 \\
$3 \mathrm{M}$ & 4.27 & 1.14 & 6.46 & 1.83 \\
$6 \mathrm{M}$ & 4.19 & 1.00 & 5.52 & 1.91 \\
$9 \mathrm{M}$ & 4.25 & 0.96 & 5.25 & 2.06 \\
$1 \mathrm{Y}$ & 4.34 & 0.93 & 5.26 & 2.25 \\
$\mathrm{Communication}$ & indexes & & & \\
DEO & 0.12 & 0.39 & 2.50 & -1.50 \\
WEO & 0.00 & 0.30 & 2.00 & -2.00 \\
MPI & -0.02 & 0.37 & 2.50 & -2.00 \\
\hline
\end{tabular}

where Comdays $_{t}^{i}$ denotes days of communication events and $Z D_{i}^{h}$ is a vector of macroeconomic variables used as controls that are explained above.

\section{Data and communication indexes}

\subsection{Data sources and variables definitions}

The focus of the paper is the interbank money market that is supposed to be directly influenced by the PBC's monetary policy communication. The PBC conducts its open market operations in this market. SHIBOR the most liberalized and important money market rates since 2006, are used as proxies for money market performances. The aim is to see whether the PBC's communication has a significant effect on the market. The daily data and central bank communication indexes cover an eight-year period, from 2010:01 to 2017:12. The inter-bank rates are sourced from the Shanghai Stock Exchange (SSE) and SSE database while the macroeconomic announcements and communications are gleaned from the PBC.

The summary statistics of the SHIBOR rate along with the indexes are reported in Table 1. It is apparent from the table that there is excess volatility, clustering and fat tail distributions. The series are subjected to a battery of unit root tests that include the ADF, the PP and the KPSS tests, to determine their level of integration. The results are reported in Table 2, which have all agreed that the series are stationary on first difference. However, the results of 1-week to 1-month rates suggest that the series are stationary on levels $I(0)$, but the remaining are non-stationary on levels, but stationary on first difference, $I(1)$. These have subsequently been noted and dealt with appropriately in the estimations.

\subsection{The communication indexes}

The PBC's communication indexes are constructed and used in this paper; they consist of those on domestic economic outlook, world economic outlook, and domestic monetary policy inclinations. Based on the what-to-communicate question, economic outlooks are about future macroeconomic conditions that have shown that they have effects on financial markets in developed economies (e.g., Rosa 2011; Hayo et al. 2012). However, 
Table 2 Unit root test

\begin{tabular}{|c|c|c|c|c|c|c|}
\hline \multicolumn{3}{|l|}{$\mathrm{ADF}$} & \multicolumn{2}{|l|}{ PP } & \multicolumn{2}{|l|}{ KPSS } \\
\hline & Level & 1st Diff & Level & 1st Diff & Level & 1st Diff \\
\hline \multicolumn{7}{|c|}{ SHIBOR from overnight to 1 -year } \\
\hline $\mathrm{O} / \mathrm{N}$ & $-8.13 * * *$ & & $-8.44 * * *$ & & $0.52 \# \# \#$ & \\
\hline $1 \mathrm{~W}$ & $-4.68 * * *$ & & $-7.33 * * *$ & & 0.84 & $0.02 \# \# \#$ \\
\hline $2 \mathrm{~W}$ & $-4.73 * * *$ & & $-5.71 * * *$ & & $0.56 \# \# \#$ & \\
\hline $1 \mathrm{M}$ & $-5.24 * * *$ & & $-4.85 * * *$ & & $0.55 \# \# \#$ & \\
\hline $3 \mathrm{M}$ & -2.33 & $-13.25 * * *$ & -2.34 & $-21.13 * * *$ & $0.52 \# \# \#$ & \\
\hline $6 \mathrm{M}$ & -2.09 & $-11.03 * * *$ & -2.08 & $-22.98 * * *$ & $0.58 \# \# \#$ & \\
\hline $9 \mathrm{M}$ & -2.11 & $-8.98 * * *$ & -2.08 & $-19.20 * * *$ & $0.64 \# \# \#$ & \\
\hline $1 \mathrm{Y}$ & -2.04 & $-10.27 * * *$ & -2.01 & $-18.77 * * *$ & $0.68 \# \# \#$ & \\
\hline \multicolumn{7}{|c|}{ The overall communication indexes } \\
\hline DEO & $-44.93 * * *$ & & $-45.16^{* * *}$ & & 1.43 & 0.04\#\#\# \\
\hline WEO & $-42.76^{* * *}$ & & $-43.14 * * *$ & & $0.50 \# \# \#$ & \\
\hline MPI & $-19.04 * * *$ & & $-44.28 * * *$ & & $0.23 \# \# \#$ & \\
\hline
\end{tabular}

The $* * *, * *$ and $*$ indicate significance at the $1 \%, 5 \%$ and $10 \%$ levels, respectively; the \#\#, \#\# and \# indicate insignificance at the $1 \%, 5 \%$ and $10 \%$ levels, respectively

economic outlook in the literature normally focuses on domestic economy as well as the central banks' views conveyed about the world economy. Therefore, communication index on world economic outlook is necessary. As discussed above, central bank communication is conventionally divided into formal and informal. Using the criteria in the literature explained, the formal communications are summarized minutes of meetings, monetary policy reports, international financial market reports and financial stability reports. Informal communications, on the other hand, are interviews, testimonies, conferences and speeches of central bankers.

Before carrying out the analysis, qualitative communication data are transformed into quantitative ones. The widely-used approach to quantify central bank communication is through coding. This is done by analysing aspects of communication such as future monetary policy inclination (tightening or easing), the positive or negative views about economic outlook, hawkish or dovish words, informative and uninformative, and the media's favourableness, etc. These are generally coded from +1 to -1 or +3 to -3 , respectively. Then, these coded communication data are transformed into communication indicator, an index (e.g., Berger et al. 2011a, b). The Swiss Economic Institute has developed monetary policy communication indicator, which has been used by some researchers including Neuenkirch (2013). However, the indicator is restrictive in terms of coverage. Hence, the most widely used technique is the coding system. This approach may have some drawbacks because of non-exclusion of subjectivity. One way of dealing with this as done by some researchers is by coding the communication data based on the media reports. A second approach is to measure communication by focusing on communication events themselves, for example, the frequency of communication per topic in central bank communication (e.g., Siklos and Bohl 2007), clarity and consistency of communication (e.g., Jansen and De Haan 2006; Jansen 2011). A third approach is through impact of communication reflected in asset prices. The usual way is to analyse this is to use dummy variables to account for the meeting days, announcement of voting records (Chortareas and Noikokyris 
2014), timing of central bank communication (Ehrmann and Fratzscher 2008). These are taken into consideration by this paper while coding to measure the communication of the PBC. Coding also allows incorporating analysis of levels and volatility of market prices. A narrative approach is used to code the communication based on tone intensity and previous communications. Since the coding process is not completely objective as biases may not be ruled out, the information is coded repeatedly and independently to deal with the problem as in Fratzscher (2008). Following the procedure, the communication is analysed repeatedly and independently up to three times. Examples are provided as follows:

Example 1 During the third Sino-French financial forum, the governor of the $\mathrm{PBC}, \mathrm{Mr}$ Zhou Xiaochuan, delivered a speech in which he stated that "although the economic growth has slowed down, we will still maintain the expansionary fiscal policy and prudent monetary policy. Excessive looseness of monetary policy will not be adopted to maintain the development and employment." This is about the economic growth and the monetary policy inclination, because no evident information implies changes of monetary policy in the near future. Therefore, the domestic economic outlook (DEC) would be 0 in this case as it indicates that the governor perceived the economy is stable and monetary policy would not change.

Example 2 In the third monetary policy report of 5th November 2013, it was emphasised that "in the near future, the economy would record growth while maintaining stability, but it still faces a lot of risks and challenges. The underlying foundation of the price level is unstable because of relative sensitivity of demand sides but we should continue to guide and to manage the inflation expectation". The information mainly focuses on inflation, therefore monetary policy inclination (MPI) index is coded as +1 indicating that PBC would place emphasis on potentially rising inflation to change the situation from the current 'unstable' to a stable one.

Overall, there are 217 overall domestic economic outlook episodes where the central bank either predicts positive or negative domestic economic trend and 144 overall world economic episodes where the central bank predicts world positive or negative global economic outlook trend. There are 207 overall monetary policy inclination indicators. That is where the bank signals monetary policy changing, either dovish or hawkish attitudes.

\subsubsection{Communication on domestic economic outlook (DEO)}

The domestic economic outlook, DEO is coded from -2 to +2 according to whether the communication suggests negative or positive outlooks, respectively. For example, if the central bank predicts that the domestic economic is very likely to be positive, then it is coded as +2 and vice versa. However, in this case, most indexes are in the interval from -1 to +1 . These can be represented as the following.

$$
D E O=\left\{\begin{array}{l}
>0 \text { positive domestic economic outlook } \\
<0 \text { negative domestic economic outlook }
\end{array}\right.
$$

where positive domestic outlook refers to the PBC's prediction that domestic economic trend would rise whereas negative index means that the bank predicts a fall in the trend.

Figure 1 reports the DEO where it illustrates that the DEO slowly decreases, which is represented by the dashed line. This is consistent with changes in China's economic 


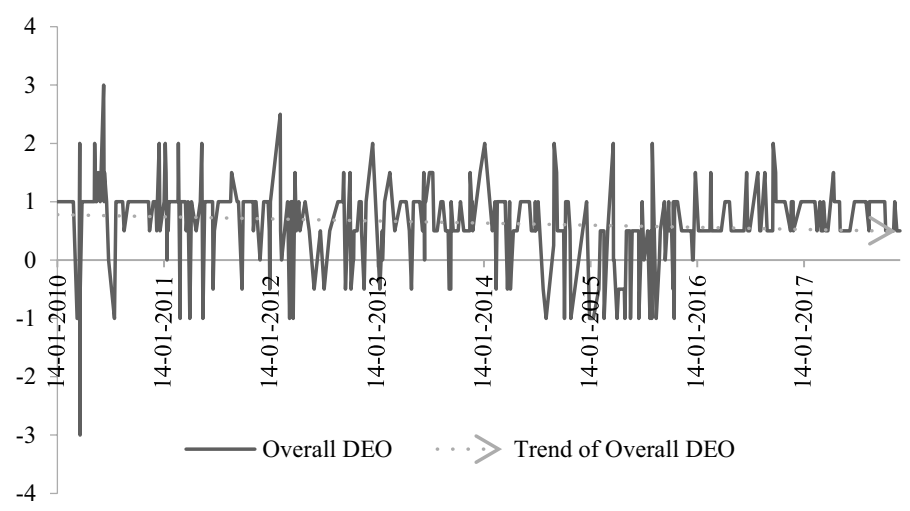

Fig. 1 DEO communication index

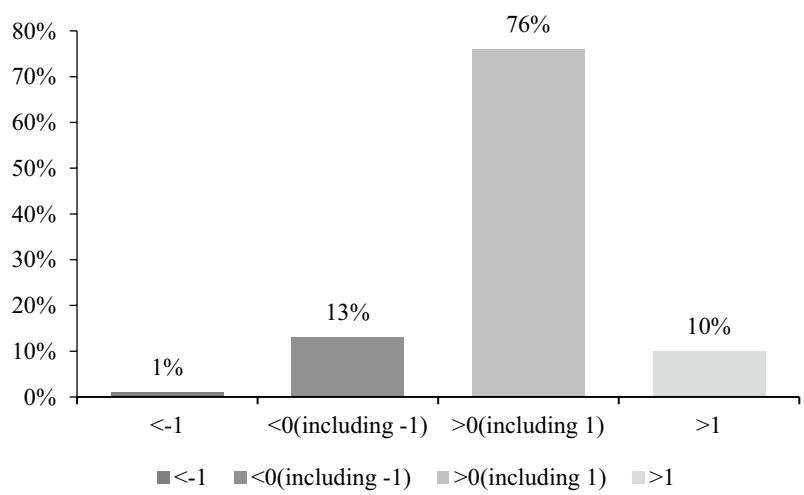

Fig. 2 Distribution of overall DEO communication indexes

conditions in recent years, mainly because of transformation of domestic economic structures, looming real estate market bubbles and the worldwide financial crisis and its aftermath.

Figure 2 summarises the episodes into negative, positive and neutral outlooks. The figure shows dominance of positive outlook communications for the period covered, 2010-2017. It accounts for $76 \%$ while negative outlook communications were $14 \%$ and neutral consists of $10 \%$ of the total communications.

\subsubsection{World economic outlook (WEO) Index}

The PBC also communicates its views about world economic outlook in a similar fashion with other central banks. The index is constructed to see if the bank's communications on foreign economic outlooks have an impact on the Chinese money market. The world economic outlook index, WEO is given as follows:

$$
W E O=\left\{\begin{array}{l}
>0 \text { positive world economic outlook } \\
<0 \text { negative world economic outlook }
\end{array}\right.
$$


Fig. 3 WEO communication indexes
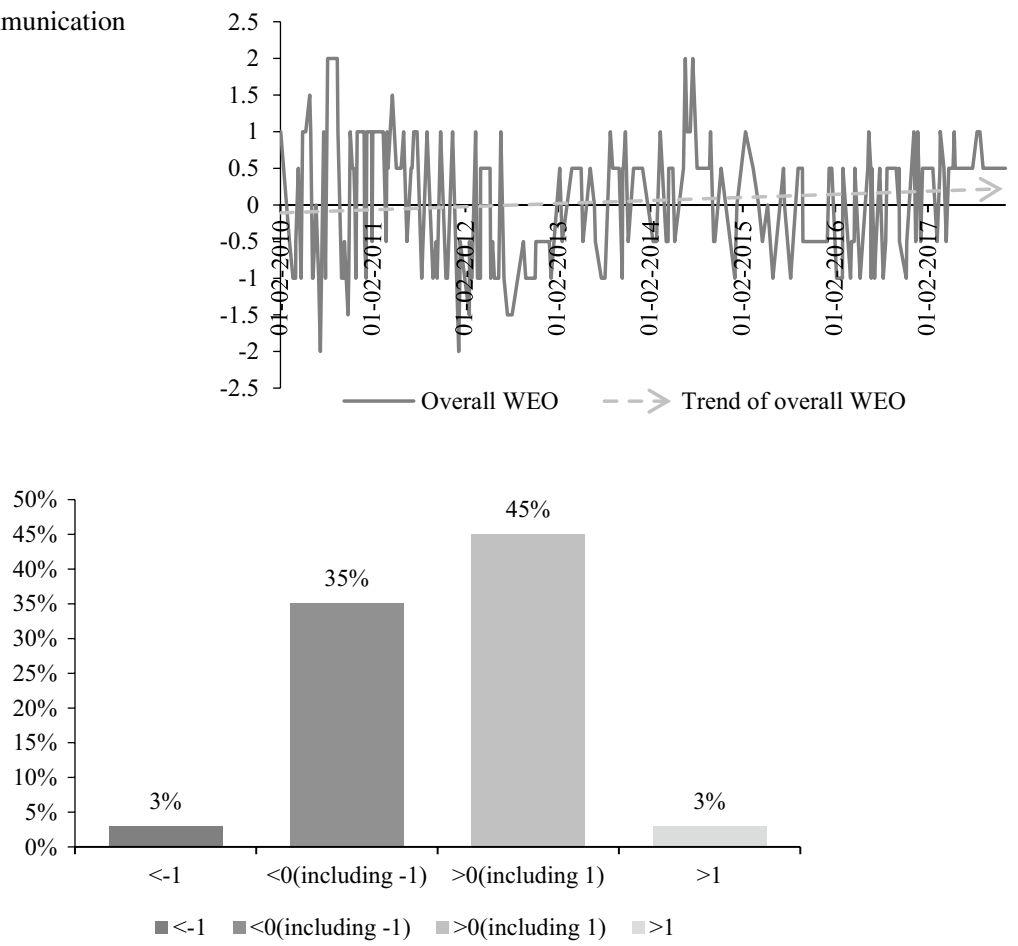

Fig. 4 Distribution of WEO communication indexes

where positive index refers to the view that world economic trend would rise while negative one, on the other hand, means that the PBC's perceives that the global outlook would trend will fall. Figure 3 displays this index, which indicates that there is a gradual but slowly increasing tendency of the world economic outlook, which corresponds with real world economic performances reported. The worldwide sub-prime crisis receded around 2012 and this is reflected in the index where the trend starts to become positive, although not substantially. However, the positive values (e.g., after 2014) are more apparent than the previous years.

Compared with percentages of domestic economic outlook indexes in Figs. 3, 4 shows that the Chinese central bank communications on world economic outlook are more conservative. Negative and positive global economic outlooks represent almost same proportions, $45 \%$ and $48 \%$, respectively.

\subsubsection{Communication on monetary policy inclination (MPI)}

This index represents the PBC's monetary policy inclination: tightening or easing signs. For example, if the governor communicates that a high inflation rate needs to be tackled with immediate effect, the communication was coded as +2 . The monetary policy inclination is coded in a similar fashion to those of DEO and WEO indexes.

$$
M P I=\left\{\begin{array}{l}
>0 \text { tightening monetary policy inclination } \\
<0 \text { easing monetary policy inclination }
\end{array}\right.
$$


Fig. 5 MPI communication indexes
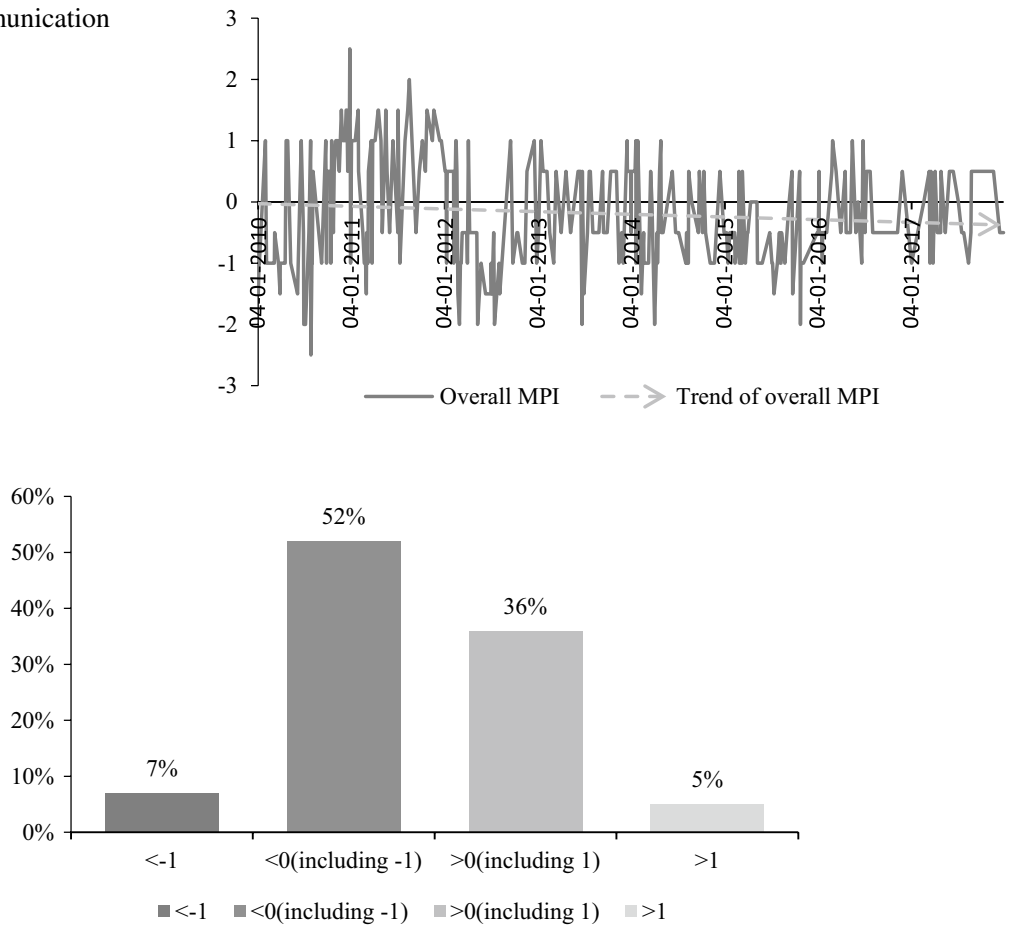

Fig. 6 Distribution of overall MPI communication indexes

where positive indicates tightening and negative refers to easing monetary policy, respectively. Since January 2011, the PBC has moved from slightly ease monetary policy stance to a more prudent monetary one. There are more tightening inclinations in 2011 than in 2010 and the trend continues with an effort to deal with rising inflation, which is shown in Fig. 5. However, direction started to change as, for example, monetary policy easing was adopted since 2012. This is mainly because of the concerns about economic downward pressure. This led to the shift from the prudent monetary policy towards a slightly monetary policy easing stance. This is also captured in Fig. 6 where the monetary policy easing inclination contributes to more than half of the total communications on monetary policy index (55\%). The three constructed indexes along with the SHIBOR were displayed in Fig. 7. The figure shows that, to some extent, the three communication indexes move together with the SHIBOR (Figs. 8, 9).

\subsection{Central bank credibility: words versus deeds}

One of the essences of central bank communication is to help monetary authorities to acquire and maintain credibility. One way of investigating this is by relating the words of a central bank with its deeds. If it is found that the words match the deeds, the literature concludes that the bank is credible (see for example, Berger et al. 2011a, b). This is because if a central bank does not do what it has conveyed to the economic agents, this would undermine its credibility and market confidence. In contrast, high central bank credibility could command the market confidence and, therefore, allows the bank to be in a better position 


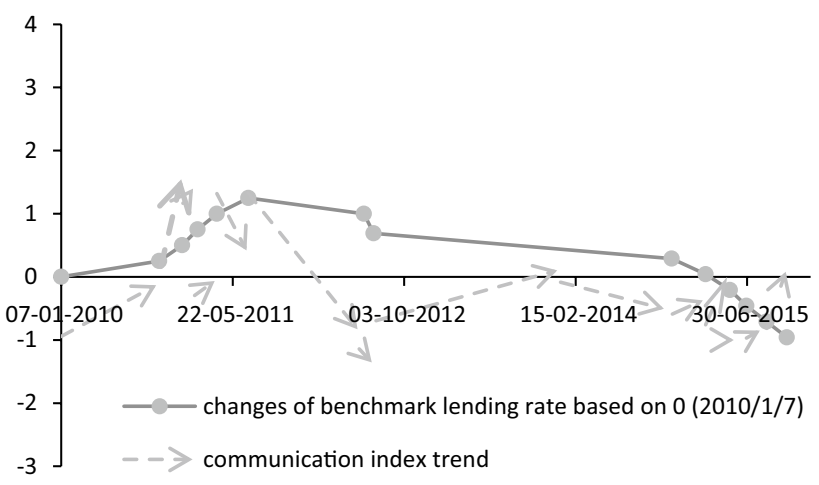

Fig. 7 Trend comparison of interest rates and MPI index

Fig. 8 Trend comparison of RRR and MPI index
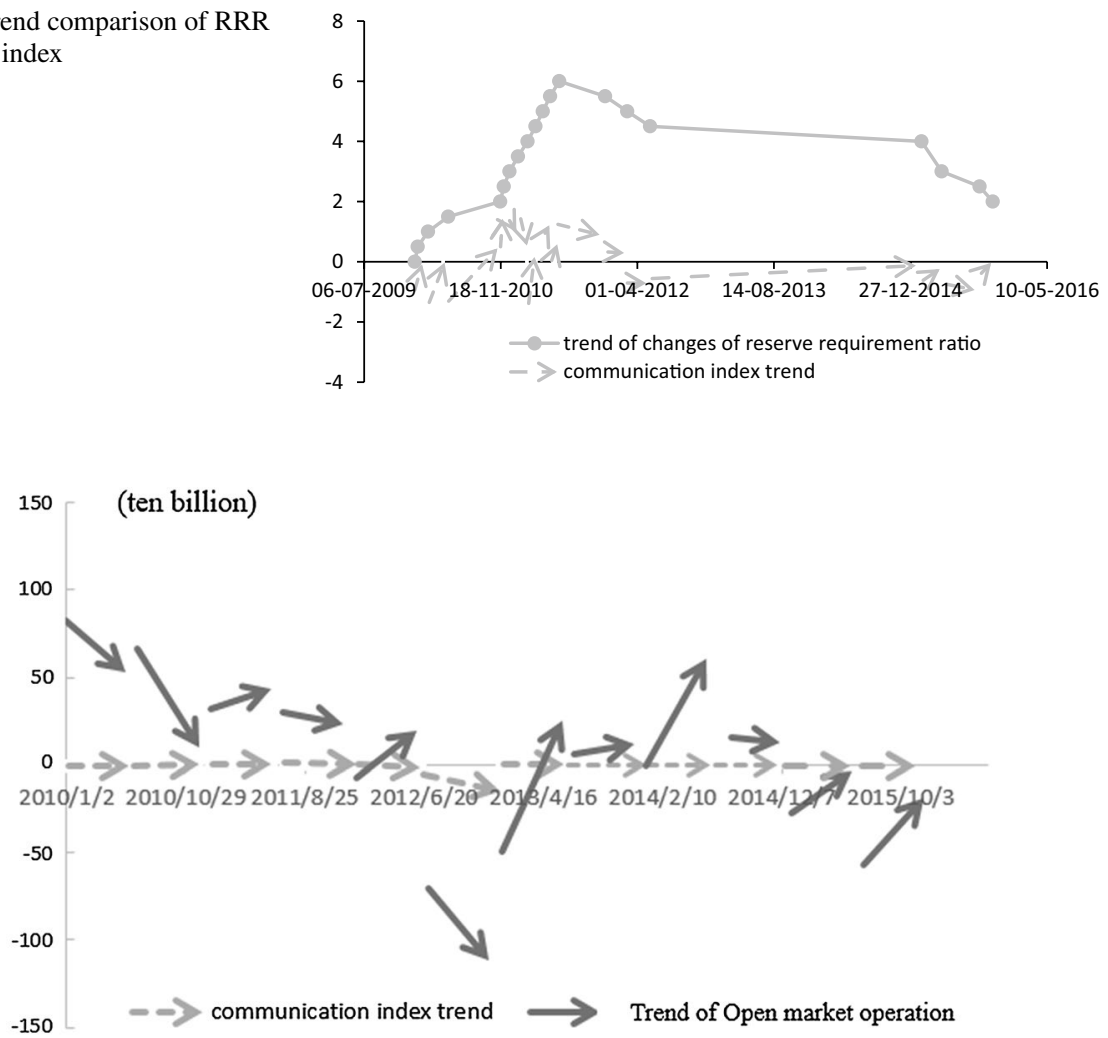

Fig. 9 Trend comparison of open market operations and MPI index

to manage market expectations. It is along this line that this paper tries to match the PBC's deeds with its words. It is difficult to match the central banks' words match deeds exactly. However, as argued by Berger et al. $(2011 \mathrm{a}, \mathrm{b})$ central bank communications on changes in monetary policy (moving either from contractionary to expansionary and vice versa) 
Fig. 10 Trend comparison of policy rate changes (benchmark rates plus RRR) and MPI index

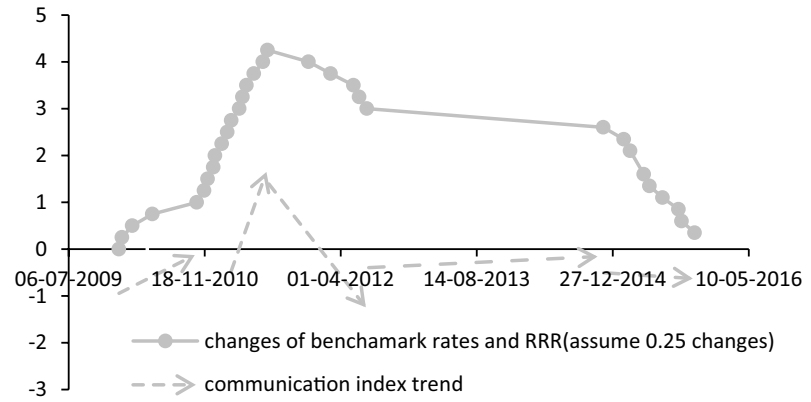

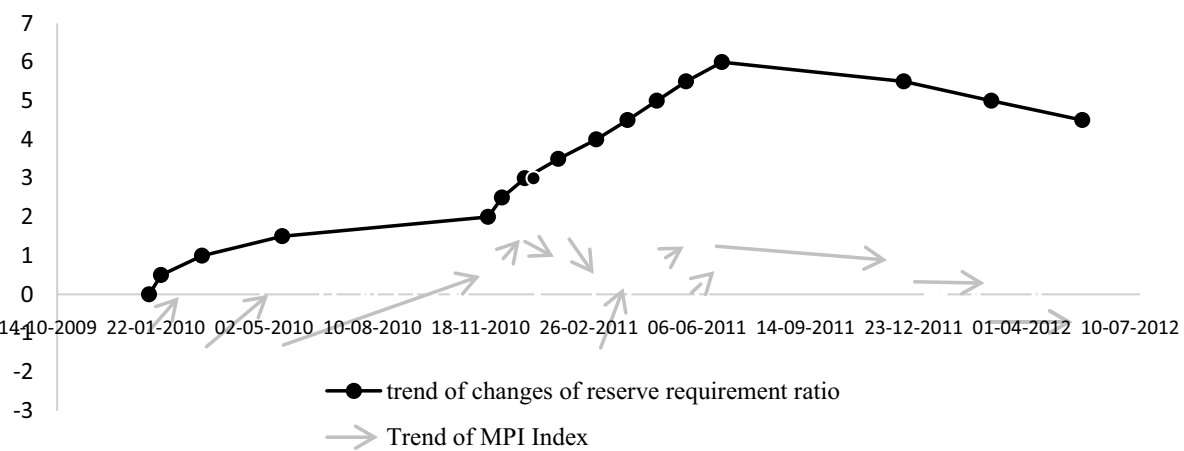

Fig. 11 Trend comparison of RRR and MPI index

should correlate with the banks' actions. That is the sign of the correlation between communications and actions in this regard should be positive (Berger et al. 2011a, b). ${ }^{5}$

The PBC relies on the benchmark interest rates, reserve requirement ratio (RRR), and open market operation as its main monetary policy tools, although it does not regularly change either its benchmark interest rates or reserve requirement ratios (23 irregular changes for the period covered). Accordingly, the monetary policy inclination communication index and the PBC's monetary policy actions are compared. The comparison is conducted in each of the policy changing intervals to look at the correlation between their words and deeds.

The first one is trend comparison between benchmark interest rates (average of benchmark interest deposit and lending rates) and monetary policy inclination communication index. The analysis is carried out for the whole sample period, which is reported in Fig. 10. The figure indicates that in the last period (07/06/2012 to the end of the sample), it is not clear that communication positively correlates with the policy actions. One of the reasons might be due to no benchmark changes from the period. However, computing the trend after January 2014, a similar direction between words and deeds of the PBC is apparent. This might signal that communication is provided in order to manage economic agents' expectations for advance policy changes.

\footnotetext{
${ }^{5}$ Correlation here should not be thought as causation. The aim here is not to investigate any causal relationship between the two, but to find out if the bank does what it says it will do in terms of monetary policy changes.
} 


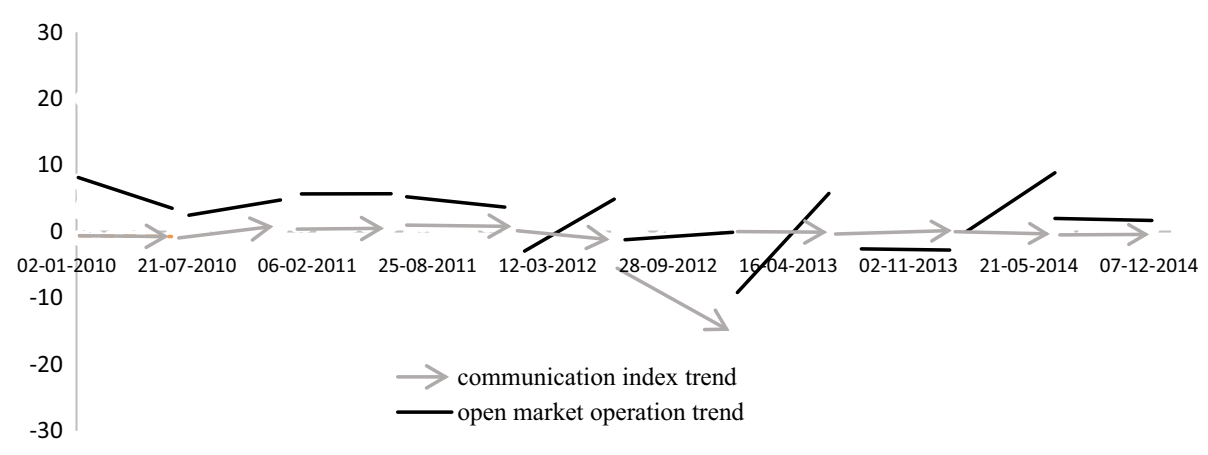

Fig. 12 Trend comparison of open market operations and MPI index

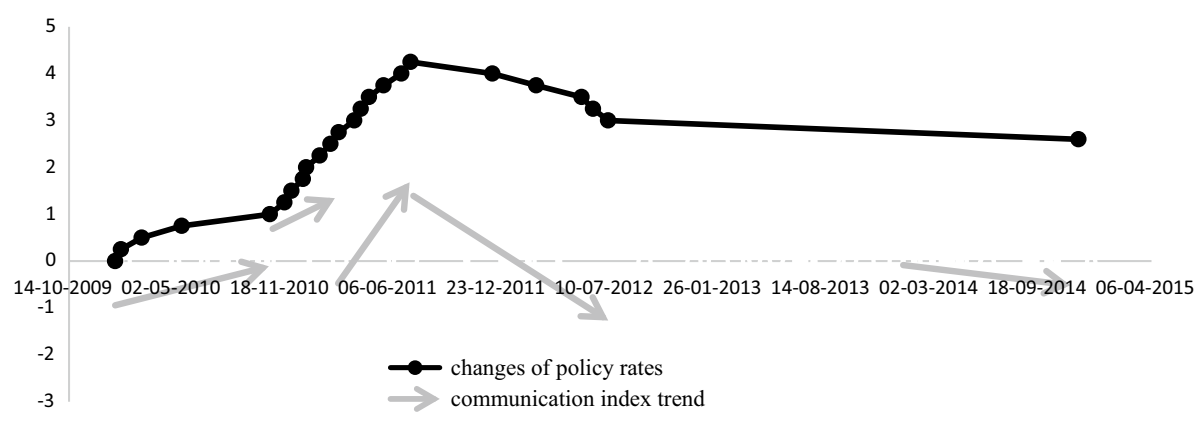

Fig. 13 Trend comparison of policy rates (repo rates plus RRR) and MPI index

Figure 11 relates the RRR and the MPI index. This is by running a correlation between the changes in RRR and MPI index. The results show that, in general, the communication index trend and changes of RRR tend to move together. These are open market operations that focuses on the total amount of repurchase and reverse repurchase together every half year.

Figure 12 reports the relationship between interest rates and the MPI, which illustrates that, in most of the period, the two trends move in the same direction, however they diverge during the last two years of the period covered. Finally, trends of MPI and changes of the policy rates along with the RRR were compared, which are depicted in Fig. 13 displaying that, in general, communication indexes move with policy rates.

As there are four apparent intervals (i.e. two increasing and two decreasing trends) in Fig. 13, they are used to examine whether the adaptive communication changes are significantly and positively related to the following changes of policy rate. Therefore, the independent variable is the accumulative changes of average benchmark interests and reserve requirement ratios based on the changed order along the timeline. The explanatory variables are the accumulative changes of communication index in each policy changing interval, and three dummy variables (i.e. $D_{i}$ where $i=1-3$ ) as proxies for the intervals. Since the policy rates changed irregularly, the time-adjusted data have been used to deal with this. Trend comparison shows that most of the trends of communication index and the trends of policy rates seem to move together. However, the last policy interval is almost half of the total five-year time interval. Therefore, the changes of 
Table 3 Expected signs of the coefficients on SHIBOR

\begin{tabular}{lll}
\hline & Mean & Volatility \\
\hline DEO & + & - \\
WEO & + & - \\
MPI & + & - \\
\hline
\end{tabular}

communication index are likely to be not clear, and the time-adjusted policy rate is also much larger than the previous data. Due to this special case of the long interval without policy rate changes, the analysis concentrates on the first three intervals are focused. The estimated model is given as:

$$
\Delta r_{t}=\alpha+\eta r_{t-1} \beta \Delta C I_{t}+D_{i}+\varepsilon_{t}
$$

where $r_{t}$ is time adjusted policy rates, $C I_{t}$ is the communication index and $D_{i}$ represents the interval dummies explained above. The estimated results are reported in Table 2, which show that the relationship between policy changes in policies and communication is positive in each time interval. Furthermore, the values are decreasing. Reasons for this could be that the open market operations have the power in the 'words and deeds' analysis, and it also might be that the central bank credibility has changed, or the communication index is not complete enough to capture the entire relationship. In general, based on these analyses above, it shows that the words of the PBC, at least, partly match their deeds.

\section{The estimations and the discussions of the results}

\subsection{The PBC's communication on the interbank money market}

As discussed above, EGARCH and GARCH models are estimated. GARCH $(1,1)$ was used because it handles skewness and kurtosis better and produces slightly better significant results and smaller numbers of information criteria (i.e., SIC and AIC) in this case. Table 3 summarises the expected signs of the coefficients on the SHIBOR rates. The coefficients on the mean of all the indexes are expected to be positive while those on the volatility to be negative. The results containing at least one significant coefficient in either mean or variance equation are reported in this paper. In addition, some periods of one-year SHIBOR are with no changes at all, overnight SHIBOR $(\mathrm{O} / \mathrm{N})$ to nine-month SHIBOR $(\Delta 9 \mathrm{M})$ are mainly estimated, which are shown in Table 4 with figures that sums the SHIBOR performance of each maturity for better comparison.

The first half of Table 4 shows that communication indexes have positive effects on most of SHIBOR series. Variance of communication on domestic economic outlook increases whereas all variance of the world economic outlook index shows a decrease. The variance of the overall communication on monetary policy inclination increases up to three-month SHIBOR where it starts to decline. For the absolute effects, both mean and variance show an increasing marginal trend. The communication on monetary policy inclination has larger effects than the other two as demonstrated by the sizes of the coefficients. Communication on world economic outlook has significant effects although smaller than those of domestic economic outlook. Also, communication on world economic outlook reduces market volatility. 


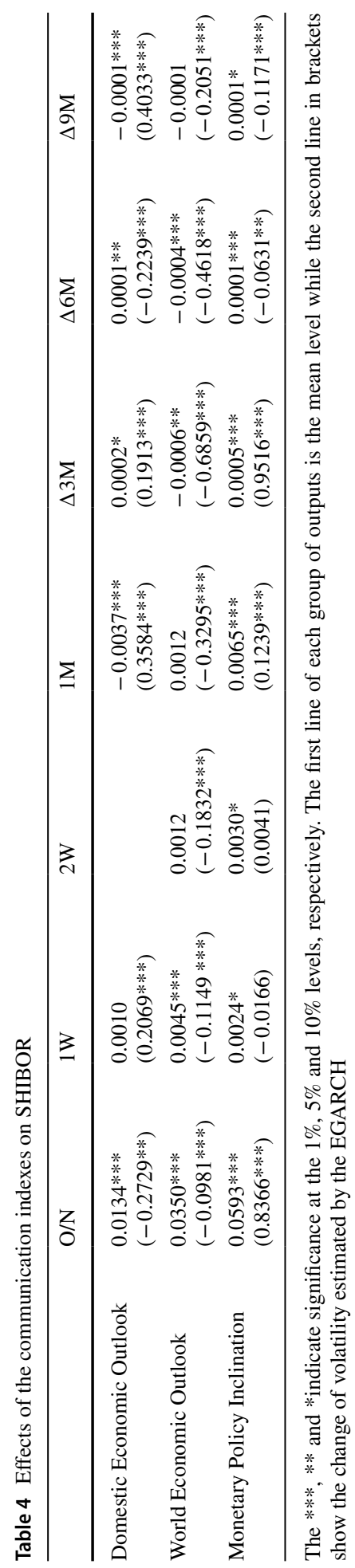




\subsection{Formal versus informal communication}

Since above findings suggest that the PBC's communication has effects on the country's money markets, it would be meaningful to examine the PBC's communication in more detail. One of the important points suggested by the literature is the communication channel. For example, it is worthwhile to assess effects of formal and informal communication, addressing the 'how-to-communicate' question. According to the communication data (i.e., formal or informal), the three overall communication indexes are transformed and extended to six communication indexes (e.g., formal monetary policy communication index and informal monetary policy inclinations). ${ }^{6}$ It is noticed that the PBC does make efforts on anti-corruption communication (69 communication events) to accompany the anti-corruption waves in the country. It would be interesting to see the effects of this emphasis. Very little research analyses this announcement effect; however, Chinese government and the central bank clearly convey their increasing tendency to deal with corruption. We focus on the interbank money market where the PBC has a direct influence. China has a rather urgent problem of corruption, it is believed nationally that communication attributes to domestic economic outlook, because more anti-corruption waves are likely to be advantageous to a brighter economy.

The results on the channels of communications are contained in Table 5, which are consistent with those reported in Table 3 and show some improvement in the marginal effects. The results show that informal monetary policy has the biggest effects $(0.5)$ on the overnight rates but decline to 0.3 on the 9-month rates. Furthermore, compared with formal communication, informal communication (e.g. speeches) performs better in this market. In terms of volatility, the informal communication reduces volatility while formal communication demonstrates a different effect. This could lead to some policy implications. For unique emphasis on anti-corruption communication, it significantly decreases the variance and shows an increase in the mean value. It is argued that the anti-corruption communication is beneficial to the anti-corruption campaigns which is believed to lead to a better economic performance. From this perspective and this unique feature of China, anticorruption communication could belong to the domestic economic outlook. In this way, the indexes of the domestic economic outlook have larger effects than the indexes of the world economic outlook.

\subsection{Communication strategies of the PBC}

The above analysis shows that communication of the PBC has significant effects on the interbank money market. Furthermore, comparison between communication channels suggests that communication strategies matter for performance of communication. Therefore,

\footnotetext{
${ }^{6}$ It can be argued that distinction between the formal and informal communication, particularly in the Chinese context may seem to be artificial as clear distinction between the two may be blurred. This is a plausible argument. However, what the paper did here is to use the criteria in the literature to group the communications into the two groups and to see if ad hoc statements and clarifications provided by the Bank's officials have any effect or not. Therefore, the PBC's formal communication regarded are the monetary policy reports while informal communication are those statements made by mostly the governor and the MPC's members in occasions such as conferences, dinners with the private and public sectors, etc. However, further investigations on whether distinction of communications into formal and informal communications matters for some countries such as China is either relevant or not, which is beyond the scope of this paper.
} 


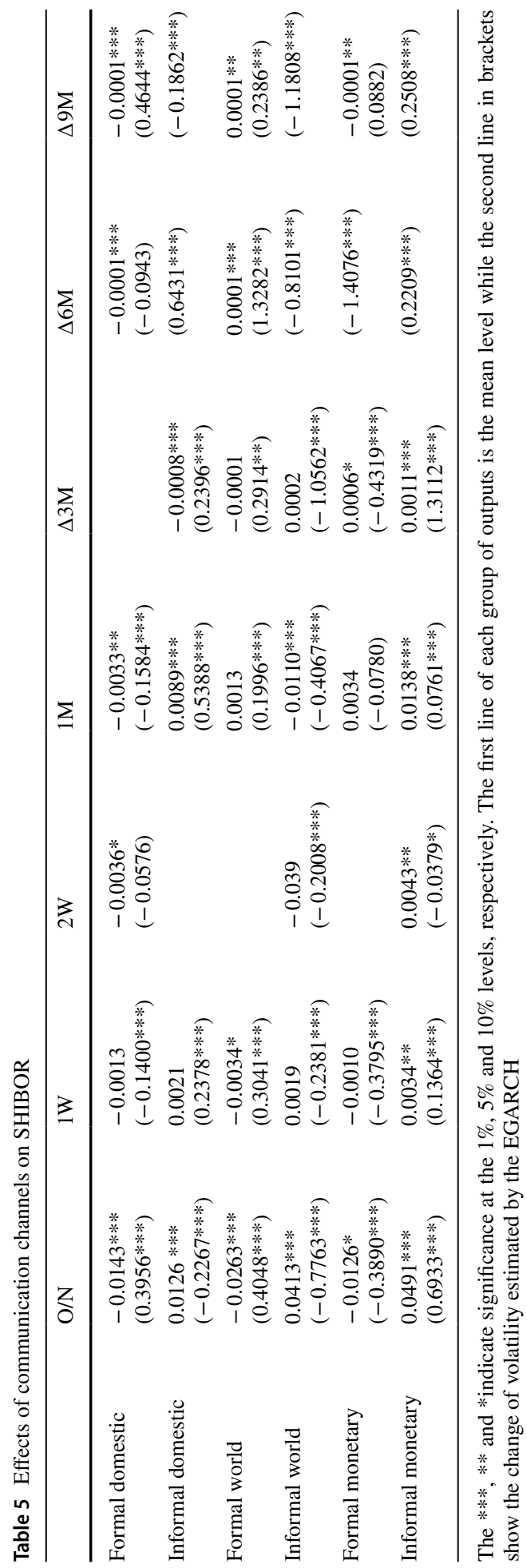


the following section has a further look at communication strategies of the PBC, particularly the governor's communication channels and strategies.

\subsubsection{The governor's communication}

The PBC's communication data reveal that the governor's communication accounted for a large amount of the total communication events (28\%), which is similar for most of central banks. Based on this, the governor's communication is likely to be important. The governor's communications can be categorized into two groups: speeches (43 events) and general communication. Researchers (e.g., Siklos and Bohl 2007; Hayo and Neuenkirch 2013; Ji and Zhou 2011) place emphasis on the overall governor's speeches, however, it would be possible to extend the depth of this analysis. The anti-corruption communication is related by the governor, then this information is added into control variables for a 'purer' effect of governor's communication.

The governor's communication was analysed to check whether it has significant effects on the money market. GARCH $(1,1)$ model performs better than the GARCH $(1,1)$ in this case and the modified model used takes the following form:

$$
\begin{gathered}
r_{t}=a_{0}+a_{1} r_{t-1}+\beta_{1} \text { Overallcom }_{t}+\beta_{2} \text { Governor' }^{\prime} C+\gamma Z_{t}+\epsilon_{t} \\
\log \left(\sigma_{t}\right)=\omega+a_{5} \log \left(\sigma_{t-1}^{2}\right)+a_{6}\left[\frac{\left|\mu_{t-1}\right|}{\sqrt{\sigma_{t-1}^{2}}}-\sqrt{\frac{2}{\pi}}\right]+a_{7} \frac{\left|\mu_{t-1}\right|}{\sqrt{\sigma_{t-1}^{2}}}+\lambda_{1} O C D+\lambda_{2} G C D+\gamma Z D_{t}^{h}
\end{gathered}
$$

where the OCD in Eq. (9) is the days of communications and GCD refers to the days of governor's communication. The estimated results are reported in Table 6. It can be seen from the table that the governor's overall communication has significant effects on the SHIBOR. The results of the governor's communications increase the mean and decrease its volatility significantly. Dummy variables were constructed and used to check whether the governor's general information and speeches have different effects. The lower part of Table 6 reports that all the mean coefficients respond positively to the governor's speech that also shows more ability to reduce market volatility. This may indicate that speeches by the governor have significant impact on the Chinese money markets.

\subsubsection{PBC's communication strategies}

Three specific communication strategies of the PBC are analysed, which are fixed testimony, high-frequency senior officials' communication, and same-day communication. During the data collection, some apparent communication strategies were noticed, and it would be interesting to see whether they are generally effective.

(i) Fixed Testimony Strategy

The PBC has put increasing efforts on its communication in recent years. It mostly communicates irregularly, however, this unique strategy with four-fixed press conferences each year was introduced from January 2013. The fixed date of communication could attract more attention, because the public is likely to anticipate and prepare for this communication. The press conference of the European Central Bank is an exact example. The announcement effects of this strategy are analysed with the help 


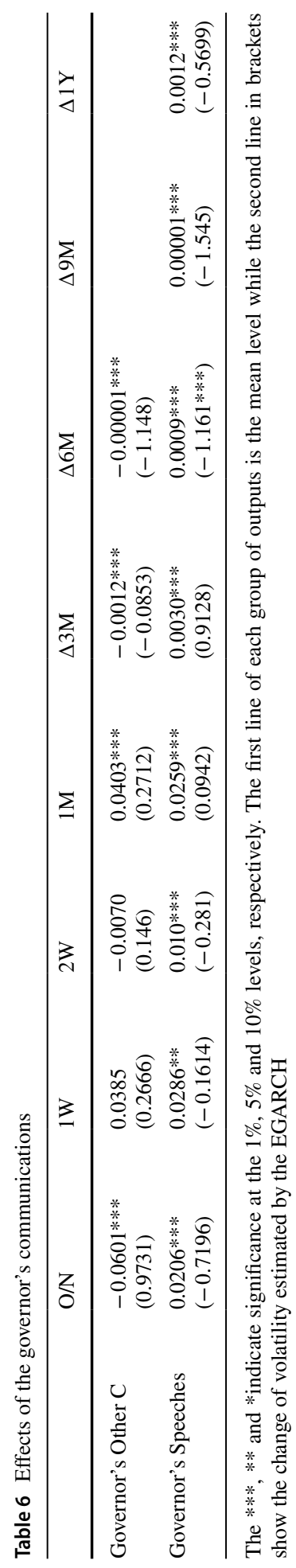


Table 7 Estimation for high-frequency senior officials' communication

\begin{tabular}{|c|c|c|c|}
\hline $\mathrm{O} / \mathrm{N}$ & $1 \mathrm{~W}$ & $2 \mathrm{~W}$ & $1 \mathrm{M}$ \\
\hline \multicolumn{4}{|c|}{ High-frequency strategy } \\
\hline $\begin{array}{c}0.2433 \\
(0.4075)\end{array}$ & & & $\begin{array}{l}0.1473 * * * \\
(-0.0431) \\
\end{array}$ \\
\hline$\Delta 3 \mathrm{M}$ & $\Delta 6 \mathrm{M}$ & $\Delta 9 \mathrm{M}$ & $\Delta 1 \mathrm{Y}$ \\
\hline $\begin{array}{l}-0.0157 * * * \\
(-0.6819)\end{array}$ & $\begin{array}{l}0.0044 * * * \\
(-0.1216)\end{array}$ & $\begin{array}{l}0.0052 * * * \\
(-0.5177)\end{array}$ & $\begin{array}{l}0.0022^{* * * *} \\
(0.3720)\end{array}$ \\
\hline
\end{tabular}

The $* * *, * *$ and $*$ indicate significance at the $1 \%, 5 \%$ and $10 \%$ levels, respectively. The first line of each group of outputs is the mean level while the second line in brackets show the change of volatility estimated by the EGARCH

of dummy variables based on the EGARCH $(1,1)$ model presented in Eq. (8). The evidence in Table 7 shows that most of the mean and volatility are positive and negative, respectively, which are consistent with the conjecture is that communication indexes or announcement effects should positively influence the levels of SHIBOR and negatively impacts the volatility. The fixed testimony strategy started in January 2013 when the PBC has already moved towards a monetary policy easing inclination. The monetary policy easing inclination seems to have been well understood as well as assimilated these signals correctly. Therefore, this newly introduced fixed testimony strategy has some effective ability to influence the Chinese money market in a desired direction.

(ii) Strategy of High-Frequency Senior Officials' Communication

In the first five months of 2011, information about previous macroeconomic performance was frequently communicated, especially the path and the future policy direction emphasised. Each communication by senior officials provided rather comprehensive information. The effect of this communication strategy, or these unique communication events, is of interest. Therefore, information contained is different from economic outlook or monetary policy inclination and needed to be examined separately. The conjecture here is that this information could affect volatility due to the relatively extensive information contained which is similar to the one analysed by Reeves and Sawicki (2007) on the UK.

The first half of Table 7 reports the estimated results which show that in the short run, the high-frequency communication strategy reduces both the mean and volatility, however, it seems to show increasing effects on volatility in the 3-month to a year's rates. This information mainly contains the path and focus of future monetary policy inclinations, which is unique to other communications, the hypothesis is supported by the findings that it creates news and volatility in the market. The results reported here are consistent with those in the extant literature.

(iii) Same-Day Communication Strategy (Consistency or Dispersion)

Central bank communication sometimes hits markets on the same day whether on purpose or not. Therefore, what would be the effects of this same-day communication? Would it have a strengthening effect on the market or otherwise. Based on these ideas, three overall communications and the communications that hit the market on the same day are of primary interests. To conduct this analysis, 48 days with same-day communication were further categorized into two variables, the 
Table 8 Estimation for same-day communication

\begin{tabular}{|c|c|c|c|c|}
\hline & $\mathrm{O} / \mathrm{N}$ & $1 \mathrm{~W}$ & $2 W$ & $1 \mathrm{M}$ \\
\hline Double effect & $-0.0385^{* * *}$ & $-0.0131 * *$ & & $0.0083^{* *}$ \\
\hline $\mathrm{DEO}$ & $\begin{array}{l}0.0077 \\
(0.2778 * * *)\end{array}$ & $\begin{array}{l}0.0042 \\
(0.4421)\end{array}$ & $-0.0148 * * *$ & $\begin{array}{l}0.0021 * * * \\
(1.1332 * * *)\end{array}$ \\
\hline WEO & $\begin{array}{l}0.0605 \\
(0.8534 * * *)\end{array}$ & & & \\
\hline \multirow[t]{2}{*}{ MPI } & $\begin{array}{l}-0.0045^{*} \\
\left(-1.1252^{* * *}\right)\end{array}$ & $\begin{array}{l}0.0436 \\
(-0.7910 * * *)\end{array}$ & $\begin{array}{l}0.0076 * * * \\
(-0.1572 * * *)\end{array}$ & $\begin{array}{l}0.0052 * \\
(-0.3613 * * *)\end{array}$ \\
\hline & $\Delta 3 \mathrm{M}$ & $\Delta 6 \mathrm{M}$ & $\Delta 9 \mathrm{M}$ & $\Delta 1 \mathrm{Y}$ \\
\hline Double Effect & & $0.0018 * * *$ & $0.0001 * * *$ & \\
\hline DEO & $\begin{array}{l}-0.0040 * * * \\
(0.1754)\end{array}$ & $(0.9016 * * *)$ & $(-0.4294 * * *)$ & $(-1.5964 * * *)$ \\
\hline WEO & $\begin{array}{l}0.0050^{* *} \\
\left(-1.3005^{* * *}\right)\end{array}$ & $\begin{array}{l}-0.0014 * * \\
(-0.4947 * * *)\end{array}$ & $\begin{array}{l}0.0003 * * * \\
(-0.8690 * * *)\end{array}$ & $(-1.1029 * * *)$ \\
\hline MPI & $\begin{array}{l}0.0042 * * \\
(1.3171 * * *)\end{array}$ & $\begin{array}{l}-0.0001 * * * \\
(0.0990)\end{array}$ & $\begin{array}{l}-0.0002 * * * \\
(1.6722 * * *)\end{array}$ & $\begin{array}{l}0.0013^{* *} * \\
\left(3.3643^{* * *}\right)\end{array}$ \\
\hline
\end{tabular}

The $* * *, * *$ and $*$ indicate significance at the $1 \%, 5 \%$ and $10 \%$ levels, respectively. The first line of each group of outputs is the mean level while the second line in brackets show the change of volatility estimated by the EGARCH

same-day communication on domestic and world economic outlook together (EC), and the same-day communication on monetary policy inclination (MP). Then, the days ( 5 days) that contain both economic outlook and monetary policy inclination were considered. An interaction slope dummy variable was used when both sameday communication together hit the market. For example, say the double same-day effects. Other two dummy variables were proxies for effects of each type of same-day communication. The mean equation of the $\operatorname{EGARCH}(1,1)$ model for analysis takes the following form:

$$
r_{t}=a_{0}+a_{1} r_{t-1}+\beta_{1} \operatorname{Com}_{t} * S D_{D}+\beta_{2} S D_{E C}+\beta_{3} S D_{M P}+\gamma Z_{t}+\epsilon_{t}
$$

where $S D_{D}$. is the double effect dummy, $S D_{E C}$. is the same-day communications on economic outlooks, and $S D_{M P}$ is the same-day communications on monetary policy inclination. Table 8 shows that double-effect variable is negative. Same-day communication about overall economic outlook and monetary policy inclination are found with more negative values. However, the two variables in the variance equation significantly reduce market volatility particularly in the long run. Therefore, strengthening eects have not been found. This leads to some more thoughts. A closer look at the data shows dispersed communications on the same day, which brings a question: are the communications prevented inhibited the supposedly strengthening effects? This is generally consistent with literature (e.g., Berger et al. 2011a, b; Erhmann and Fratzshcer 2013). Emphasis is placed on the mean value of coefficients and the results about volatility is not clear.

Table 9 reports the coefficients with at least one significant value. The same-day effects without dispersion results are shown to be mostly positive. From the line of 'dispersion effect', the evidence suggests that dispersion communication indeed has negative effects on 


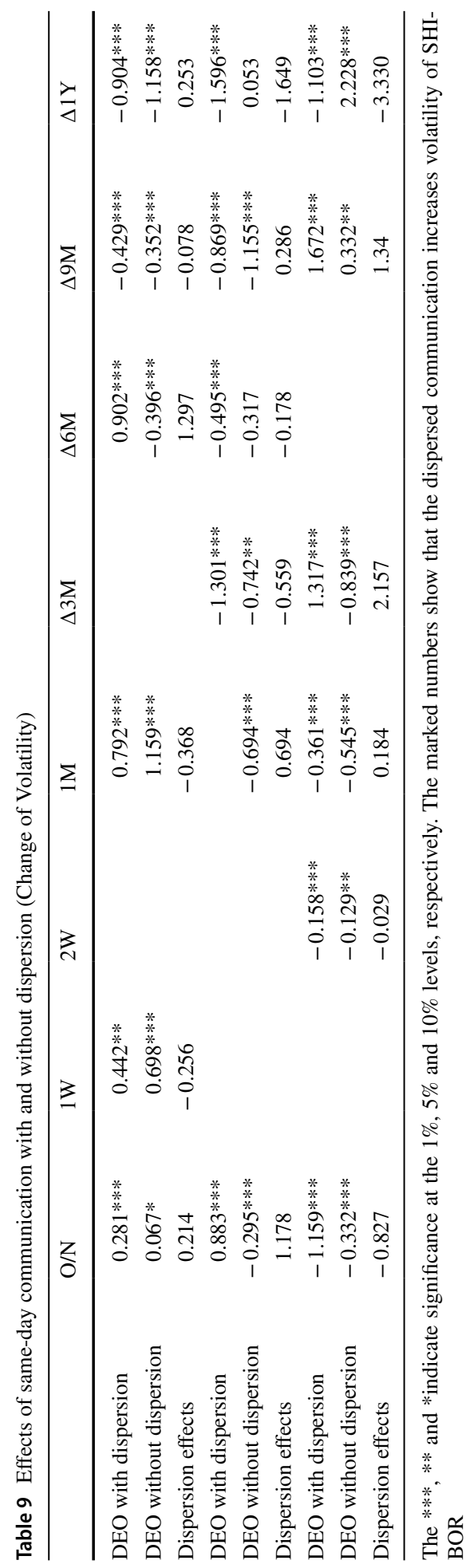


Table 10 Estimation for 'foreign exchange' talks

\begin{tabular}{llllll}
\hline & US Dollar & British Pound & Euro & Hongkong Dollar & Japanese Yen \\
\hline FX talks & $0.0168 * * *$ & $-0.0105^{* * *}$ & $-0.0611^{* * *}$ & $-0.0491 * * *$ & $-0.0004 * * *$ \\
& $(-3.8680)$ & $(-1.6835)$ & $(-3.0267)$ & $(-2.3795)$ & $(-1.9141)$ \\
\hline
\end{tabular}

The $* * *, * *$ and $*$ indicate significance at the $1 \%, 5 \%$ and $10 \%$ levels, respectively. The first line of each group of outputs is the mean level while the second line in brackets show the change of volatility estimated by the EGARCH

the means of the market price. The model was then estimated again without dispersion and was compared with the one with dispersion. It is found that four of five double same-day communications were dispersed.

Table 10 reports estimations on communications regarding the foreign exchange markets. This covers the US dollar, British Pound, the Euro, the Hong Kong dollar and Japanese Yen. The results indicate that the communication has negative moderating effects on all the currencies' volatility. However, the results on the coefficients on the mean are all negative, except that of the US dollar. This might be due to the dominance of the US dollar in the global foreign exchange markets. ${ }^{7}$

\section{Conclusion, policy implication and possible extensions}

The increasing importance of central bank communication makes it a worthwhile research interest. The main role of central bank communication is to move the markets in order to: (i) improve market efficiency and (ii) decrease market volatility (Blinder et al., 2008). This topic has attracted considerable attention, but mostly on developed economies. Although emerging and developing economies have become important in the global output, effectiveness of central bank communications in these economies has been largely overlooked. This paper attempts to fill the gap by looking at the effects of the PBC's communications on Chinese interbank money market.

The empirical results show that the PBC's words match its deeds. In addition, its communications have some significant effects on the money market. With respect to the whatto communication question, the supposedly responsive interbank money market indeed shows a large response, particularly to communication about monetary policy inclination. A similar finding is the effect of informal communication, which suggests policymakers and market observers watching more informal communication such as speeches of the central bank governor and its officials. The governor's speeches are found to be influential on the money market. Furthermore, emphasis on anti-corruption communication has effects in reducing market volatility. The three communication strategies of the $\mathrm{PBC}$ have significant effect on the money market. Finally, dispersed communications, in particular those that

\footnotetext{
7 This paper sets to investigate effects of PBC's communication on the Chinese money market. It could be argued that looking at the effects on the entire economy will be a good thing. This is particularly relevant in the light of recent findings by Lai and Goh (2019) that recent changes in Chinese exchange rate policies not only precipitated response from the entire economy, but also in other economies. The argument is very plausible, however, it is beyond the scope of this paper.
} 
affect the market on the same day, should be treated with care when communicating to the public and the markets as they tend to increase market volatility.

Some of the policy implications of the findings include the following: (i) the PBC's can use communication as an effective policy in the interbank money market in China. (ii) Global economic outlook communication needed to be carried out with a caution. (iii) The three communication strategies adopted by the bank were able to reduce market volatility and the bank, should, therefore, strengthen them for greater benefits. The foreign exchange communication is particularly significant and therefore can be used as required to calm down the markets, particularly the one between RMB and the US dollar, which is more central to Chines investors. (iv) Consistency in communication is beneficial.

A potential extension of the work is to investigate the effect of central bank communication on other Chinese financial markets such as foreign exchange markets. It would be also possible to investigate communication channels with more details such as comparison between monetary policy reports and speeches which could shed light on what kinds of communication channels are more appropriate for certain markets. Another important extension is to look at the effects of central bank communication on an entire economy.

Open Access This article is distributed under the terms of the Creative Commons Attribution 4.0 International License (http://creativecommons.org/licenses/by/4.0/), which permits unrestricted use, distribution, and reproduction in any medium, provided you give appropriate credit to the original author(s) and the source, provide a link to the Creative Commons license, and indicate if changes were made.

\section{References}

Andersson M, Dillen H, Sellin P (2006) Monetary policy signalling and movements in the term structure of interest rates. J Monet Econ 52:1815-1855

Berger H, De Haan J, Sturm JE (2011a) Does money matter in the ECB strategy? New evidence based on ECB communication. Int J Finance Econ 16:16-31

Berger H, Ehrmann M, Fratzscher M (2011b) Monetary policy in the media. J Money, Credit Bank 43(4):689-709

Blinder AS (1998) Central banking in theory and practice. The MIT press, Cambridge and London

Blinder AS, Ehrmann M, Fratzscher M, De Haan J, Jansen DJ (2008) Central bank communication and monetary policy: a survey of theory and evidence. J Econ Lit 46(4):910-945

Born B, Ehrmann M, Fratzscher M (2012) Communicating about macro-prudential supervision- a new challenge for central banks. Int Finance 15(2):179-203

Buchel K (2013) Do words matter? The impact of communication on the PIIGS' CDS and bond yield spreads during Europe's sovereign debt crisis. Eur J Political Econ 32:412-431

Campbell JR, Evans CL, Fisher JDM, Justiniano A (2012) Macroeconomic effects of Federal Reserve forward guidance. Brookings Paper on Economic Activity, spring

Chortareas G, Noikokyris E (2014) Monetary policy and stock returns under the MPC and inflation targeting. Int Rev Finance Anal 31:109-116

Cornad C, Lamla MJ (2010) The high-frequency response of the EUR-USD exchange rate to ECB communication. J Money, Credit Bank 42(7):1391-1417

De Haan J (2008) The effect of ECB communication on interest rates an assessment. The Rev Int Org 3:375-398

De Haan J, Eijffinger SCW, Rybinski K (2007) Central bank transparency and central bank communication. Eur J Polit Econ 23:1-8

Ehrmann M, Fratzscher M (2007) The timing of central bank communication. Eur J Polit Econ 23:124-145

Ehrmann M, Fratzscher M (2008) Purdah—on the rationale for central bank silence around policy meetings. J Money, Credit Bank 41(2-3):517-528

Ehrmann M, Fratzscher M (2013) Dispersed communication by central bank committees and the predictability of monetary policy decisions. Public Choice 157:223-244

Fraztzscher M (2008) Communication and exchange rate policy. J Macroecon 30:1651-1672 
Geraats PM (2006) Transparency of monetary policy: theory and practice. CESifo Econ Stud 52(1):111-152 Hayo B, Neuenkirh M (2011a) Bank of Canada communication, media coverage, and financial market reactions. Econ Lett 115:369-372

Hayo B, Neuenkirh M (2011b) Does the currency board matter? US news and Argentine financial market reaction. Appl Econ 45:4034-4040

Hayo B, Neuekirch M (2013) Do Federal Reserve presidents communicate with a regional bias? J Macroecon 35:62-72

Hayo B, Kutan AM, Neuenkirch M (2010) The impact of U.S. central bank communication on European and pacific equity markets. Econ Lett 108:172-174

Hayo B, Kutan AM, Neuenkirch M (2012) Federal Reserve communication and emerging equity markets. Southern Econ J 78(3):1041-1056

Hussain SM (2011) Simultaneous monetary policy announcements and international stock markets response: an intraday analysis. J Bank Finance 35:752-764

Jansen DJ (2011) Does the clarity of central bank communication affect volatility in financial markets? evidence from Humphery-Hawkins testimonies. Contemp Econ Policy 29(4):494-509

Jansen DJ, De Haan J (2006) Look who's talking: eCB communication during the first years of EMU. Int J Finance Econ 11:219-228

Ji Z, Zhou X (2011) Can central bank communication be a monetary policy tool? Stud Int Finance 2:25-34 (in Chinese)

Kadapakkam P, Krause T, Tse Y (2015) Exchange traded funds, size-based portfolios and market efficiency. Rev Quant Finance Acc 45(89):89-110

Kahn G (2007) Communicating a policy path: the next frontier in central bank transparency? Econ Rev First Quart 92:25-51

Knutter R, Mohr B, Wagner H (2011) The effects of central bank communication on financial stability a systematization of the empirical evidence. Discussion Paper of Department of Economics, University of Hagen, No. 463

Lai W-C, Goh K-L (2019) Impact of Chinese Yuan devaluation on the dependence structure: the Archimedean copula approach. Rev Pac Basin Financ Mark Polic 22(01):1-27

Lamla MJ, Lein SM (2011) What matters when? The impact of ECB communication on financial market expectations. Appl Econ 43:4289-4309

Masawi Becksndale, Bhattacharya Sukanto, Boulter Terry (2018) Does the information content of central bank speeches impact on the level of exchange rate? A comparative study of Canadian and Australian Central Bank communications. Rev Pac Basin Financ Mark Polic 21:1. https://doi.org/10.1142/S0219 091518500054

Neuenkirch M (2011) Managing financial market expectations: the role of central bank transparency and central bank communication. Eur J Polit Econ 28:1-13

Neuenkirch M (2013) Central bank transparency and financial market expectations: the case of emerging markets. Econ Syst 37:598-609

Reeves R, Sawichi M (2007) Do financial markets react to Bank of England communication? Eur J Polit Econ 23:207-227

Rosa C (2011) Words that shake traders stock market's reaction to central bank communication in real time. J Empir Finance 18:915-934

Siklos PL, Bohl MT (2007) Do actions speak louder than words? evaluating monetary policy at the Bundesbank. J Macroecon 29:368-386

Steeley J (2004) Stock price distribution and news: evidence from index option. Rev Quant Finance Acc 23:229-250

Zeng Y, McLaren J (2015) The impact of large public sales of government assets: empirical evidence from the Chinese stock markets on gradual and offer-to-get approach. Rev Quant Finance Acc 45(1):137-173

Publisher's Note Springer Nature remains neutral with regard to jurisdictional claims in published maps and institutional affiliations. 